\title{
Articulação Ensino-Extensão: Experiência na Educação de Jovens e Adultos nas Escolas da Rede Municipal de Belo Horizonte
}

\section{Teaching-extension articulation: experience in the education of youth and adults at schools of the Belo Horizonte municipal network}

\author{
Lucas de Araújo Fernandes $^{1 *}$, Letícia Bernardes de Castro ${ }^{1 *}$ \\ ${ }^{1}$ Graduandos da Faculdade Ciências Médicas de Minas Gerais \\ * Autores para correspondência: luca_araujo@hotmail.com; Ilbdc@hotmail.com
}

\section{RESUMO}

Introdução: $\mathrm{O}$ ensino universitário vem preparando o acadêmico com o conteúdo teórico, mas também com práticas que buscam aumentar o contato do estudante com a comunidade. $\mathrm{O}$ presente relato apresenta as atividades realizadas pelo projeto de extensão Ressuscit $A C ̧ \tilde{A} O$, realizado por acadêmicos da Faculdade de Ciências Médicas de Minas Gerais. Justificativa: Os episódios de parada cardiorrespiratória são muito prevalentes no Brasil e no mundo, sendo necessário capacitar a população leiga sobre técnicas de ressuscitação cardiopulmonar. No caso dos professores do EJA, essa ação é relevante, uma vez que parte dos alunos apresenta idade elevada. Objetivos: Discutir as atividades do projeto Ressuscit $A C ̧ A \tilde{O} O$ e seus resultados, assim como seu impacto e os benefícios de sua implementação. Materiais e métodos: $\mathrm{O}$ projeto realizado capacitou professores da rede de Educação de Jovens e Adultos (EJA) de escolas municipais de Belo Horizonte sobre as técnicas de ressuscitação cardiopulmonar. Discussão: Os projetos de extensão são recursos que propiciam uma articulação entre os conteúdos aprendidos na sala de aula com a sua extensão prática na comunidade. Durante a execução desse projeto, foram alcançados 26 professores do EJA, os quais foram capacitados com o protocolo de ressuscitação cardiopulmonar destinado a leigos. Conclusão: $O$ projeto Ressuscit $A C ̧ \tilde{A} O$ atingiu seus objetivos, e a articulação entre ensino e extensão foi percebida pelos acadêmicos participantes, que tiveram a função de ensinar e qualificar corretamente os professores.

Palavras-Chave: Reanimação Cardiopulmonar; Ensino; Relações Comunidade-Instituição.

\begin{abstract}
Introduction: University education has been preparing the academic with theoretical content, but also with practices that seek to increase student contact with the community. The article in question reports the activities carried out by the extension project RessuscitAÇÃO, executed by academics from the Faculty of Medical Sciences of Minas Gerais. Rationale: Cardiorespiratory arrest episodes are very prevalent in Brazil and worldwide, and it is necessary to train the population on cardiopulmonary resuscitation techniques. In the case of Youth and Adult Education (EJA) teachers, this action is relevant, since part of the students are of advanced age. Objectives: To discuss the activities of the RessuscitAÇÃO project and its results, as well as its impact and the benefits of its implementation. Materials and methods: The project trained teachers from the EJA network of municipal schools in Belo Horizonte on cardiopulmonary resuscitation techniques. Discussion: Extension projects are resources that provide an articulation between the content learned in the classroom and its practical extension in the community. During the execution of this project, 26 EJA teachers were reached and trained with the cardiopulmonary resuscitation protocol. Conclusion: The RessuscitAÇÃO project achieved its objectives and the articulation between teaching and extension was perceived by the participating academics, who had the function of correctly teaching and qualifying teachers.
\end{abstract}

Keywords: Cardiopulmonary resuscitation; Teaching; Community-Institutional Relations.

\section{Introdução}

O perfil do profissional de saúde vem se alterando de modo que a formação tem se tornado mais generalista, humanista, crítica e reflexiva, preparando o indivíduo para atuar em todos os níveis de atenção à saúde. Dessa forma, as 
universidades buscam, cada vez mais, aumentar o contato dos alunos com as comunidades através de disciplinas ou projetos que contribuam para a prevenção e a promoção de saúde (MOURA et al., 2012).

Nesse cenário, um dos recursos disponíveis para os centros de educação são os projetos de extensão. Esses projetos constituem vasto recurso de aprendizado: possibilitam não só um contato do aluno com a comunidade, mas também uma ferramenta para o desenvolvimento de habilidades e competências importantes para a interação humana (OLIVEIRA \& JÚNIOR, 2015).

A extensão traz benefícios para a comunidade, já que funciona como um canal de troca de informações entre as universidades e os setores sociais. Nesse sentido, como apenas uma parcela restrita da população tem acesso aos conhecimentos gerados na universidade, essa prática acadêmica é essencial para a democratização do acesso a esses saberes (SCHEIDEMANTEL, KLEIN \& TEIXEIRA, 2004).

Os projetos de extensão têm um papel fundamental na formação do profissional com uma consciência cidadã. Ao funcionar como uma via de duas mãos, a extensão leva conhecimentos e/ou assistência à comunidade, enquanto o aluno aprende sobre a realidade, valores e cultura da população (SCHEIDEMANTEL, KLEIN \& TEIXEIRA, 2004; OLIVEIRA \& JÚNIOR, 2015).

Dentre esses conhecimentos não disseminados a nível populacional, destaca-se a ressuscitação cardiopulmonar (RCP), uma informação prática e teórica que tem a capacidade de salvar vidas. Nesse sentido, de acordo com dados epidemiológicos do livro Medicina de Emergência da USP (2017), 80\% das paradas cardiorrespiratórias (PGR) extra-hospitalares são quadros passíveis de reversão com o atendimento adequado e com a desfibrilação precoce (MARTINS, BRANDÃO \& VELASCO, 2017).

De acordo com Gonzalez (2013), mais de 630 mil brasileiros são vítimas de morte súbita devido à PCR extra-hospitalar, sendo que cerca de 50\% das paradas ocorrem diante de um leigo. Desse valor, a mortalidade das vítimas antes de chegar ao hospital pode chegar até a $90 \%$ no território brasileiro. Entretanto, caso o socorro seja fornecido de maneira rápida e eficaz, as chances de sobrevivência da vítima podem alcançar até 70\%.

Programas educativos de treinamento e intervenções práticas, tais como prestar socorro e RCP de maneiras adequadas, como no caso do projeto RessucitAÇÃO, se fazem extremamente necessários. Ademais, depois da conclusão dessas propostas, é preciso realizar uma análise desses projetos a fim de identificar os pontos positivos e negativos do método utilizado, para melhorar a experiência subsequente.

Tendo em vista o cenário atual, no qual o perfil demográfico e epidemiológico da população está em transição e a expectativa de vida aumentou, o conhecimento sobre a RCP se faz necessário. Dessa forma, o projeto de extensão torna-se um recurso importante não só para expandir os conhecimentos sobre as PGR, mas também para aumentar o número de cidadãos que sejam capazes de prestar socorro adequado às vítimas, aumentando as chances de sobrevivência destas (MARTINS, BRANDÃO \& VELASCO, 2017).

Este relato visa não apenas a expor as experiências da extensão desenvolvida, mas também a promover uma discussão sobre os benefícios da implementação de projetos que democratizem o conhecimento para a população através de propostas de ensino não formal. Por fim, esta revisão também se propõe a analisar o impacto dessa ação no ponto de vista dos integrantes do projeto.

\section{Relato de Experiência}

Trata-se de uma análise do projeto RessucitAÇÃO, de suas atividades e dos objetivos alcançados. Esse projeto se propôs a ensinar e a capacitar os professores da rede de Educação de Jovens e Adultos (EJA) de Belo Horizonte no protocolo proposto para a ressuscitação cardiopulmonar. A proposta do projeto era o ensino teórico, por meio de apostilas e de uma aula expositiva, seguido das demonstrações e de manejos práticos em manequins. 
O público-alvo desse projeto, que propunha promover a capacitação na RCP, foi constituído pelos professores da rede EJA de Belo Horizonte. A rede, destinada à alfabetização ou ao término do Ensino Fundamental de indivíduos acima de quinze anos, tem uma faixa etária bastante heterogênea, que vai desde jovens na adolescência até indivíduos na terceira idade.

Dessa forma, ao capacitar os professores, para que estes futuramente sejam disseminadores desse conhecimento, é possível atingir uma base populacional bem ampla, inclusive de indivíduos mais vulneráveis às doenças cardiovasculares, ou seja, a população com idade mais avançada. Ademais, de acordo com Mello (2000), as informações transmitidas de uma maneira não formal permitem que a comunidade reflita a respeito do que lhe é transmitido, e possibilitam que o professor, simultaneamente, crie e se torne um investigador sistemático de sua prática.

O projeto RessuscitAÇÃO, realizado durante todo o ano de 2018, dividiu-se em três etapas: planejamento, execução e análise dos resultados. Compuseram essa ação cinco acadêmicos do curso de Medicina $-3^{\circ}$ e $4^{\circ}$ ano -, uma acadêmica do curso de Enfermagem $-1^{\circ}$ ano - e uma acadêmica do curso de Fisioterapia $-2^{\circ}$ ano - da Faculdade de Ciências Médicas de Minas Gerais (FCMMG). As duas orientadoras do projeto são graduadas em enfermagem e docentes da FGMMG.

Primeiramente, durante o planejamento, desenvolveu-se o material utilizado para a capacitação dos professores do EJA: uma apostila com as explicações e um roteiro baseado no Basic Life Support (BLS) para leigos. Após isso, foram escolhidas quatro escolas municipais de Belo Horizonte que possuíam o programa EJA e estavam localizadas no raio de $1,5 \mathrm{~km}$ da faculdade. Ainda na fase de planejamento, as professoras responsáveis pelo projeto realizaram a capacitação dos acadêmicos com o BLS no Laboratório de Simulação da Faculdade de Ciências Médicas de Minas Gerais (LabSim).

A fase seguinte do projeto foi a execução. Nessa etapa, os acadêmicos, divididos em grupos, foram até as escolas escolhidas para a capacitação dos professores do EJA. Em cada escola, eram levados manequins para o treino da massagem cardíaca e as apostilas para os professores do EJA. No total, 26 professores participaram do projeto e receberam certificados de participação emitidos pela FCMMG.

A última etapa do projeto compreendeu a análise dos resultados e de toda a experiência do projeto.

Com o desenvolvimento do projeto em questão foi alcançado o objetivo de ensinar 26 professores do EJA sobre os protocolos e as manobras específicas para casos de PCR. Dessa forma, espera-se que esses profissionais da educação estejam preparados caso esses eventos ocorram com algum aluno do EJA ou em outras situações fora do seu ambiente escolar.

A questão do processo da articulação ensino-extensão durante o desenvolvimento desse projeto foi claramente percebida pelos alunos da faculdade FGMMG. Antes de capacitar os professores do EJA, os acadêmicos tiveram que aprender o protocolo e as manobras específicas para casos de PCR, através do ensino do BLS pela faculdade. Dessa forma, foi essencial aprender corretamente para estar apto a ensinar corretamente. Esse aprendizado foi importante tanto para o projeto quanto para os próprios acadêmicos no futuro, tendo em vista que esses conhecimentos são muito utilizados por médicos durante toda a carreira profissional.

Após o aprendizado desse tema na faculdade, a etapa de execução prática do projeto foi iniciada com as visitas nas escolas municipais participantes do EJA previamente escolhidas. Os acadêmicos ensinaram os professores do EJA e tiveram a experiência de docência enquanto ainda são alunos na faculdade de Medicina. A sensação de ensinar e qualificar uma pessoa com um conhecimento específico pode ser gratificante e estimulante. No caso desse projeto, o qual transmite uma informação que tem o potencial de produzir um impacto significativo na comunidade atendida, o sentimento pode ser ainda mais perceptível. 
Durante a realização do projeto, os acadêmicos envolvidos perceberam o impacto que pode ser gerado na sociedade. $\mathrm{O}$ ensino de técnicas tão relevantes como a ressuscitação cardiopulmonar tem a capacidade de alterar a realidade de uma comunidade, uma vez que mais pessoas se tornam aptas a agir em casos de PCR. Esse tipo de informação deve ser repassado para o máximo de pessoas possível. Dessa forma, esse projeto abrange corretamente o conceito de projeto de extensão, levando em conta que permite uma ligação entre a sala de aula universitária e a comunidade em geral.

Por fim, o público beneficiado pelo projeto também percebeu a relevância deste tema e elogiou bastante a intervenção realizada. Em geral, é possível afirmar que a avaliação do público-alvo deste projeto foi muito positiva, uma vez que os professores do EJA sugeriram que ele continue nos próximos anos, buscando atender mais escolas em outras regiões de Belo Horizonte.

\section{Conclusão}

A iniciativa de desenvolver um projeto de extensão deve sempre considerar o impacto que se pretende gerar na comunidade atendida. $\mathrm{O}$ objetivo principal é oferecer uma intervenção à comunidade, considerando-se a realidade cotidiana desta. A extensão deve ser vista como uma ligação entre o ambiente universitário e a sociedade, sendo uma forma de disseminar o conhecimento aprendido nas aulas para a população em geral (MENDES, 2010). Deve-se considerar que nesse processo há um intercâmbio de saberes e experiências entre os acadêmicos da extensão e a população atendida pelo projeto (DUARTE et al., 2013).

Portanto, com essa ação nas escolas municipais de Belo Horizonte foi possível aliar o ensino com a extensão, transmitindo conhecimento sobre a conduta básica em casos de PCR para uma população específica, a qual pode beneficiar-se com essa informação no futuro. Novamente, esse deve ser sempre o objetivo dos projetos de extensão: intervir em uma comunidade e/ou população, buscando levar as informações presentes dentro do ambiente universitário para a realidade da sociedade.
Por fim, o Projeto RessuscitAÇÃO propiciou aos acadêmicos envolvidos a oportunidade de aperfeiçoarem seus conhecimentos sobre o tema discutido, além de experienciarem a docência, apesar de ainda estarem inseridos no ambiente acadêmico. Além disso, mostrou-se como uma boa oportunidade de estabelecer um vínculo entre a comunidade e o aluno, experiências pouco vivenciadas durante a graduação.

\section{Referências Bibliográficas}

DUARTE, Emeide Nóbrega; COSTA, L.; SANTOS, E.; SANTOS, J. \& MORAES, F. "Comportamento e competência em informação: uma experiência em extensão universitária". Revista ACB: Biblioteconomia em Santa Catarina, Florianópolis, vol. 18, n. 1, jan./jun. 2013, pp. 553-75.

MARTINS, Herlon Saraiva; BRANDÃO NETO, R. \& VELASCO, I. Medicina de Emergência: Abordagem Prática. Barueri: Manole, 2017.

MELLO, Guiomar Namo de. "Formação Inicial de Professores para a Educação Básica: uma (Re)visão Radical". São Paulo em Perspectiva, São Paulo, vol. 14, n. 1 , jan./mar. 2000.

MENDES, A. "Extensão Universitária: Entenda e Estenda a Importância Dessa Ideia". Anais da X Fornada de Ensino, Pesquisa e Extensão, Universidade Federal de Pernambuco, Recife, out., 2010.

MOURA, Lúcia de Fátima Almeida de Deus; PIAULINO, R.; ARAÚJO, I. \& MOURA, M. "Impacto de um Projeto de Extensão Universitária na Formação do Profissional de Egressos de uma Universidade Pública". Revista de Odontologia da Unesp, São Paulo, vol. 41, n. 6, nov./dez. 2012, pp. 348-352.

OLIVEIRA, Franklin Learcton Bezerra \& JÚNIOR, J. "Extensão Universitária: Contribuições na Formação de Discentes de Enfermagem". Revista Brasileira de Pesquisa Saúde, Vitória, ed. 17, vol. 1, jan.l mar. 2015, pp. 19-24.

SCHEIDEMANTEL, Sheila Elisa; KLEIN, R. \& TEIXEIRA, L. "A Importância da Extensão Universitária: o Projeto Construir". Anais do $2^{\circ}$ Congresso Brasileiro de Extensão Universitária, Belo Horizonte, Universidade Federal de Minas Gerais, set. 2004.

SOCIEDADE BRASILEIRA DE CARDIOLOGIA. "I Diretriz de Ressuscitação Cardiopulmonar e Cuidados Cardiovasculares de Emergência da Sociedade Brasileira de Cardiologia". Arquivos Brasileiros de Cardiologia, Rio de Janeiro, vol. 101, n. 2, supl. 3, ago. 2013, pp. 1-221. 